\title{
Retinoic acid induces differentiation in neuroblastoma via ROR1 by modulating retinoic acid response elements
}

\author{
ABHINAV ILLENDULA, NORMAN FULTANG and BELA PEETHAMBARAN \\ Department of Biology, University of The Sciences in Philadelphia, Philadelphia, PA 19104, USA
}

Received February 13, 2020; Accepted June 16, 2020

DOI: $10.3892 /$ or.2020.7681

\begin{abstract}
Neuroblastoma is the most common inheritable, solid neoplasm in children found under the age of 7 and accounts for approximately $7 \%$ of childhood cancers. A common treatment that has been prescribed for over a decade is retinoid therapy [using all-trans retinoic acid (RA)]. Treatment with this differentiating agent has been revealed to progress the cells from their stem-cell state to a mature neuronal state gaining classical neuronal characteristics, including the suppression of proliferation. However, the molecular mechanism underlying the action of RA treatment remains to be elucidated. In the present study, a novel mechanism of RA-induced differentiation via regulation of receptor tyrosine kinase-like orphan receptor 1 (ROR1) is reported. ROR1 is overexpressed in neuroblastoma but significantly downregulated in mature differentiated neurons. Hence, it was hypothesized that RA may modulate ROR1 leading to differentiation and termination of cancerous properties. Immunoblotting revealed that following RA treatment, ROR1 levels initially increased then sharply decreased by $96 \mathrm{~h}$. This was paired with synaptophysin, a mature neuron marker, sharply increasing concurrently, providing evidence of differentiation by $96 \mathrm{~h}$. Investigation of the ROR1 pathway confirmed ROR1-dependent downstream activation of the PI3K/AKT signaling axis, a growth pathway previously demonstrated to promote differentiation. Chromatin immunoprecipitation revealed an increase in RAR binding to the promoters of ROR1 and its endogenous ligand, Wnt5a. This research provided compelling evidence that RA is able to modulate the expression of ROR 1 and Wnt5a to promote differentiation through the expression of synaptophysin. This data combined with the overarching data from the scientific community regarding proliferation and other proliferative
\end{abstract}

Correspondence to: Dr Bela Peethambaran, Department of Biology, University of The Sciences in Philadelphia, 600 South 43rd Street, Philadelphia, PA 19104, USA

E-mail: b.peethambaran@usciences.edu

Key words: neuroblastoma, receptor tyrosine kinase-like orphan receptor 1, synaptophysin, retinoic acid response elements, all-trans retinoic acid, differentiation factors in early-stage neurons provides a more in-depth model of the process of differentiation in neurons.

\section{Introduction}

Neuroblastoma (NB) arises when early neuroblasts in the fetus become cancerous causing widespread nervous system impairments throughout the body including cognitive disabilities, motor function impairment, and a compromised autonomic nervous system $(1,2)$. These cancerous neuroblasts originate in the adrenal glands but can spread to other locations such as the peripheral nervous system, spinal cord, and cortical regions of the brain, leading to poor patient outcomes (3). Understanding the cellular mechanisms underlying impaired differentiation and carcinogenesis in these neuroblasts can improve future NB therapies.

The current treatments for NB include radiation therapy and chemotherapy. However, these treatments are very toxic and harmful (4). In addition, the relapse rates are markedly high, usually leading to additional chemotherapy or death (4). A therapeutic approach that has minimized side effects is retinoic acid (RA)-induced differentiation with RA analogues such as all-trans RA. RA is a naturally-occurring retinoid synthesized from vitamin A in embryos and adult vertebrates (5-7). RA has been revealed to be very effective for NB therapy in infants under 18 months with almost all patients exhibiting complete remission from cancer (5). RA analogues promote differentiation of neuroblasts to mature neurons. Since NB is a neuronal cancer of immature neuronal cells, for the change to mature neurons, classic neuronal characteristics are acquired including cell cycle arrest, termination of aggressive cell movement, and formation of stronger synapses compared to the immature cell (8).

The actions of RA are mediated by binding to nuclear RA receptors (RARs), regulating the transcriptional activity of the latter, as well as activating downstream signaling cascades (9). Upon RA binding, activated RAR binds to target DNA sequences [RA response elements (RAREs)] (10). The downstream and intermediate targets of RA-activated RAR, which contribute to neuroblast differentiation are not well studied (11). Insight into the mechanism of RA-induced differentiation via RAR would yield new targets to develop improved differentiation therapies.

The purpose of the present study was to elucidate the mechanism of RA-induced differentiation, providing insight to key 
proteins that play an important regulatory role in this process. In the present study, a novel mechanism of RA-induced differentiation via the oncofetal receptor tyrosine kinase-like orphan receptor 1 (ROR1) was described. Embryos and fetuses have been revealed to highly express ROR1 in numerous tissues, including epithelial and nervous tissue (12). There is minimal expression of ROR1 in normal adult tissues $(12,13)$ and data published from our laboratory has demonstrated a link between overexpression of ROR1 and triple-negative breast cancer cell migration and proliferation (14). Similarly, ROR1 levels have been revealed to be abnormally high in NB (15) but only minimally expressed in differentiated neurons. Notably, Wnt5a, the ligand for ROR1, is underexpressed in NB and has previously been revealed to regulate neuronal differentiation (16). RA has been demonstrated to activate the PI3K/Akt signaling pathway which is already known to be regulated by ROR1 (17). It was thus hypothesized that differentiation therapy with RA may be mediated via the ROR1 and Wnt5a signaling pathway. To corroborate this hypothesis, the changes in ROR1 followed by RA treatment as well as ROR1-knockdown experiments were investigated to reveal its role in RA-induced differentiation.

For the present study, SK-N-SH neuronal epithelial cells, which have been revealed to differentiate into mature neurons that can be easily characterized by neurite outgrowth, were used (18). This renders them particularly useful for delineating signaling pathways involved in neuronal differentiation. SK-N-SH has also been revealed to contain RAR, specifically RAR- $\alpha$, and has been previously studied in aspects such as apoptosis (11). Additionally, evidence of similar trends of ROR1 expression in SH-SY5Y cells and patient primary cells from data collected from the NCBI GEO datasets were provided.

The data from the present study provided further insight into the molecular mechanism of RA-induced differentiation and reiterated the potential of ROR 1 and its downstream proteins such as PI3K/AKT as a therapeutic target for poorly differentiated neuroblastoma.

\section{Materials and methods}

Cell culture. SK-N-SH (HTB-11; ATCC) cells were cultured using methods recommended by ATCC. Culture media was prepared using DMEM/F-12 (Lonza Group, Ltd.) supplemented with fetal bovine serum (10\%) (cat. no. TMS-013-B; EMD Millipore), penicillin (100 U/ml), and streptomycin $(0.1 \mathrm{mg} / \mathrm{ml})$ (cat. no. 516106; EMD Millipore). Cells were maintained at $37^{\circ} \mathrm{C}$ with $5 \% \mathrm{CO}_{2}$. Cell cultures were validated and routinely checked for contaminants including mycoplasma.

Differentiation of $S K-N-S H$ cells using RA. Neuroblastoma cells, SK-N-SH, were treated with $10 \mu \mathrm{M}$ all-trans RA (CAS no. 302-79-4; Cayman Chemical Company) $(19,20)$ dissolved in DMSO and diluted in culture media (final DMSO concentration, $<0.1 \%$ ) for up to $96 \mathrm{~h}$ without the addition of new culture media. AGN 193109 (product no. SML2034; EMD Millipore), a RAR inhibitor, was prepared by dissolving in DMSO to a stock solution of $1 \mathrm{nM}$ and diluted in culture media to a final concentration of $10 \mu \mathrm{M}$. Cells were then treated for $1 \mathrm{~h}$ before RA treatment and then treated in cell media containing AGN
193109 and RA for up to $96 \mathrm{~h}$ without the addition of new culture media.

Immunoblotting. Following appropriate treatments, cells were washed with 1X PBS. To extract proteins, cells were scraped with a plastic cell scraper and 1X PBS (cat. no. MT21040CV; Thermo Fisher Scientific, Inc.) and centrifuged at 5,000 x g for $10 \mathrm{~min}$. The cell pellets were lysed in RIPA buffer (150 mM NaCl, 1.0\% Triton X-100, 0.5\% sodium deoxycholate, $0.1 \%$ SDS, $50 \mathrm{mM}$ Tris, $\mathrm{pH} 8.0$ ) with $1 \mathrm{mM}$ PMSF. Protein concentrations from the supernatant were quantified utilizing the Bradford Assay using Pierce $660 \mathrm{~nm}$ Protein Assay reagent (Thermo Fisher Scientific, Inc.). The lysate was then diluted in 2X Laemmli Buffer and $355 \mathrm{mM} \beta$-mercaptoethanol (CAS 60-24-2; EMD Millipore) to be boiled for $5 \mathrm{~min}$. Protein samples (10-15 $\mu \mathrm{g})$ were loaded on a $4-15 \%$ gradient SDS-PAGE to ensure that protein concentrations were equal amongst all lanes. Following SDS-PAGE, separated proteins were transferred to nitrocellulose membranes using electrophoresis. Membranes were then blocked in 5\% milk for $1 \mathrm{~h}$ at room temperature and subsequently washed with TBS-T (20 mM Tris, $150 \mathrm{mM} \mathrm{NaCl}, 0.1 \%$ Tween-20). Primary antibody incubations were performed overnight in 5\% milk and then washed with TBS-T. Secondary anti-mouse (product no. 7076; Cell Signaling Technology, Inc.) or anti-rabbit IgGs (product no. 7074; Cell Signaling Technology, Inc.) linked with horseradish peroxidase diluted 1:1,000 were incubated at room temperature for $1 \mathrm{~h}$ and washed with TBS-T. Protein bands were imaged via immunofluorescence by SuperSignal ${ }^{\mathrm{TM}}$ West Dura Extended Duration Substrate (cat. no. 34076; Thermo Fisher Scientific, Inc.). The primary antibodies used were as follows and diluted 1:1,000 unless specifically specified differently under manufacturer recommendations: ROR1 (D6T8C; product no. 16540; Cell Signaling Technology, Inc.), GAPDH (D16H11; product no. 5174; Cell Signaling Technology, Inc.), p-AKT-ser473 (product no. 9271; Cell Signaling Technology, Inc.), AKT (C67E7; product no. 4691; Cell Signaling Technology, Inc.), p-GSK3 $\beta$-Ser9 (D17D2; product no. 8566; Cell Signaling Technology, Inc.), and GSK3 $\beta$ (D75D3; product no. 5676; Cell Signaling Technology, Inc.), $\beta$-catenin (cat. no. MA1-301; Invitrogen; Thermo Fisher Scientific, Inc.), p- $\beta$-catenin-Ser33/37 (product no. 2009; Cell Signaling Technology, Inc.), stabilized- $\beta$-catenin (product no. 9562; Cell Signaling Technology, Inc.), Wnt-5a (cat. no. NBP2-24752SS; Novus Biologicals, Ltd.), Synaptophysin (cat. no. 100298-T40; Sino Biological, Inc.), $\beta$-tubulin (product code ab21057; Abcam) and Lamin B1 (product code ab65986; Abcam).

Densitometric analysis. Densitometry of immunoblots was performed with ImageJ (v1.52a; NIH) software utilizing established methods $(21,22)$. Blots were imported to ImageJ and utilizing the 'analyze gel' feature, the areas under the curves generated from the bands were obtained for further analysis.

MTT cell viability assay. Cell viability was determined using an MTT Assay (Thermo Fisher Scientific, Inc.) according to a previously published method (14). Cells were seeded in a 96-well plate at 15,000 cells/well. A $0.3 \%$ vehicle control group was used and after $96 \mathrm{~h}$, treatment media was replaced 
with media containing MTT dye and incubated at $37^{\circ} \mathrm{C}$ with $5 \% \mathrm{CO}_{2}$ for $3 \mathrm{~h}$. Following incubation, DMSO was added and absorbance was read using a spectrophotometer at $540 \mathrm{~nm}$.

Immunofluorescence analysis. Following treatments with $10 \mu \mathrm{M}$ RA, shROR1, $10 \mu \mathrm{M}$ RA+shROR1, or DMSO Control, cells were plated in Lab-Tek chamber slides at a density of 10,000 cells/well. Cells were then fixed with pre-chilled methanol $\left(5 \mathrm{~min},-20^{\circ} \mathrm{C}\right)$, washed with PBS and blocked for $1 \mathrm{~h}$ at room temperature in 5\% BSA/PBS (blocking buffer). Primary antibody incubation was performed in blocking buffer at $4^{\circ} \mathrm{C}$ overnight. Following three PBS washes, cells were incubated with secondary antibodies Alexa-fluor-647 (Thermo Fisher Scientific, Inc.) in blocking buffer for $1 \mathrm{~h}$ at room temperature. The cells were then washed and stained with a $1-\mu \mathrm{g} / \mathrm{ml}$ DAPI/PBS solution for $2 \mathrm{~min}$ at room temperature. Confocal fluorescence microscopy at x40 magnification was performed using a Leica DMi8 microscope. All the primary antibodies are mentioned in the Immunoblotting section.

Analysis of neurite length/cell size. The length of neurites or cell size was measured using ImageJ considering the techniques published regarding simple length analysis of neurons (23). Images of the cells were imported and using the polygon shape tool, manual tracing was performed with $\sim 10-15$ cells per image to obtain cell size. The measurements were averaged to obtain the cell size of the sample. Neurite length was obtained similarly but used the line tool to manually measure the length between the middle of the soma to the tip of the longest neurite. This was performed to 10-15 cells per image and averaged to obtain the neurite length of the sample.

$\beta$-catenin luciferase reporter assay. A construct encoding a TCF/LEF luciferase reporter system (cat. no. 79787; SABiosciences) was transfected into cells at 10,000 cells/well using Lipofectamine 3000 (cat. no. L3000008; Thermo Fisher Scientific, Inc.). Expression of this construct is modulated by the TCF/LEF transcription factor system specific to the Wnt/ $\beta$-catenin signaling pathway (24). Following transfection, cells were treated with $10 \mu \mathrm{M}$ RA up to $96 \mathrm{~h}$. Following trypsinization of treated cell cultures, the cells were collected using PBS and then were pelleted by centrifugation at 5,000 $\mathrm{x}$ g for 5 min followed by removal of the supernatant. Dual-Glo ${ }^{\circledR}$ Luciferase Assay System reagent was added (100 $\mu \mathrm{l}$; cat. no. E2920; Promega Corporation). Following a 3-h incubation on ice, luminescence was read at a 10 -sec exposure per well. Luciferase measurements were normalized to protein concentrations of $0 \mathrm{~h}$ Control group. Luciferase experiments were performed as technical triplicates.

Analyzing the expression of Wnt5a and ROR1 using real-time quantitative $(R T-q) P C R$. Following treatments with $10 \mu \mathrm{M}$ RA for up to $96 \mathrm{~h}$, RNA extraction was performed using TRIzol (cat. no. 15596026; Thermo Fisher Scientific, Inc.). cDNA synthesis from the extracted RNA was performed using the SuperScript ${ }^{\mathrm{TM}}$ III First-Strand Synthesis System (cat. no. 18080051; Thermo Fisher Scientific, Inc.) according to the manufacturer's protocol. Following a 1:50 dilution of synthesized cDNA, RT-qPCR was performed with the
CFX384 Touch Real-Time PCR detection system (Bio-Rad Laboratories, Inc.) under the following conditions: i) $95^{\circ} \mathrm{C}$ for $15 \mathrm{~min}$; ii) $95^{\circ} \mathrm{C}$ for $10 \mathrm{sec}$; iii) $60^{\circ} \mathrm{C}$ for $30 \mathrm{sec}$; and iv) repeat ii and iii for 39 more cycles. The fluorophore used was SYBR Green (cat. no. 1725150; Bio-Rad Laboratories, Inc.). The ROR1 (NCBI Gene ID: 4919) and Wnt5a (NCBI Gene ID: 7474) primers used were as follows: ROR1 forward, 5'-TGT TTGTCAAGTTTGGCCCCC-3' and reverse, 5'-AGGGAA GGAATGGCGAACTG-3'; and Wnt5a forward, 5'-CTT CAGCTCCGGTTCACTGC-3' and reverse, 5'-TGGACTTCT TCATGGCGAGGG-3'. qPCR quantification utilized $2^{-\Delta \Delta C T}$ analysis (25). Stand-alone qPCR experiments were conducted as biological triplicates.

Chromatin-immunoprecipitation (ChIP) assay to analyze the binding of a RAR to RORI promoter. Immunoprecipitation of RAR-bound chromatin was performed using the Pierce Agarose ChIP Kit (cat. no. 26156; Thermo Fisher Scientific, Inc.) according to manufacturer's instructions. Briefly, 320,000 cells were plated in each well of 6-well plates and treated with RA. Cells were then fixed with chilled $1 \%$ paraformaldehyde solution at room temperature for $10 \mathrm{~min}$ and lysed. Immunoprecipitation was performed using an anti-RAR- $\alpha$ antibody (product no. 62294S; Cell Signal technology, Inc.) at a 1:50 dilution. RT-qPCR of Wnt5a and ROR1 promoter regions was performed using the following ROR1 (NCBI Gene ID: 4919) and Wnt5a (NCBI Gene ID: 7474) primers: ROR1 forward, 5'-TGTTTGTCAAGTTTGGCCCCC-3' and reverse, 5'-AGGGAAGGAATGGCGAACTG-3'; and Wnt5a forward, 5'-CTTCAGCTCCGGTTCACTGC-3' and reverse, 5'-TGG ACTTCTTCATGGCGAGGG-3'. ChIP assay experiments were conducted as technical triplicates.

Analysis of gene expression data from NCBI gene expression omnibus (GEO). In dataset GSE58070 (26), SH-SY5Y cells were treated with $5 \mu \mathrm{M}$ RA for $30 \mathrm{~min}, 1,3,6$ and 9 days. DMSO was used as a vehicle control. For each treatment, total RNA was extracted using the RNeasy Mini Kit (Qiagen) and gene expression was profiled using NimbleGen 12x135 K Homo sapiens Expression Array (PROBE_ID version 100718_HG18_opt_expr) (NimbleGen-Roche). Expression data was normalized to GAPDH using the $2^{-\Delta \Delta \mathrm{Ct}}$ method. ROR1 and Wnt5a expression data was retrieved using ID NM_005012P02481 and NM_003392P04985, respectively, in GEO2R. In dataset GSE45587 (27), BE(2)-C cells were treated with $5 \mu \mathrm{M}$ RA for 6, 24 and $72 \mathrm{~h}$. DMSO was used as a vehicle control. Genome-wide expression profiling was performed using GeneChip Affymetrix U133A microarray (GeneChip). ROR1 and Wnt5a expression data was retrieved in GEO2R using probe IDs 205805_s_at and 205990_s_at respectively. In dataset GSE120920 (28), patient-derived xenograft cultures were obtained from cerebral metastasis of a stage 4 neuroblastoma patient (NB-PDX2) and a primary tumor in the adrenal gland of a patient with stage 3 neuroblastoma (NB-PDX3). Both cell lines were MYCN amplified. Both NB-PDX2 and NB-PDX3 were treated with RA for 6 and $24 \mathrm{~h}$, with DMSO vehicle controls in both groups. Whole transcriptome analysis was performed via DRUG-Seq (29). We visualized and analyzed the data using the R2 Genomics Analysis and Visualization Platform (r2.amc.nl) (30). ROR1 and Wnt5a 
data was retrieved with probe IDs ENSG00000185483 and ENSG00000114251 respectively. All data were expressed as the mean \pm standard error of mean and statistical analysis was conducted using GraphPad Prism 7.04 (GraphPad Prism Software, Inc.).

ROR1 knockdown and overexpression. ROR1 expression was knocked down by shRNA (shROR1) (plasmid DNA seq: 5' CCGGCTTTACTAGGAGACGCCAATACT CGAGTATTGGCGTCTCCTAGTAAAGTTTTT 3') (cat. no. SHCLND-NM_005012; EMD Millipore) or overexpressed using an ROR1-overexpressing plasmid (pROR1) containing a CMV promoter (accession no. NM_005012; GenScript). Transfection of shRNA or pROR1 was performed using the Lipofectamine 3000 Reagent (cat. no. L3000008; Thermo Fisher Scientific, Inc.). Cells were plated at 300,000-400,000 cells per well in a 6-well plate. Twenty-four hours after seeding, the cells were washed with PBS. Transfection was performed in non-supplemented MEM with $1 \mu \mathrm{g}$ DNA/well for shROR1, $0.1 \mu \mathrm{g}$ DNA/well for pROR1, and/or $0.1 \mu \mathrm{g}$ DNA/well for $\beta$-catenin luciferase reporter plasmid. Cells were transfected for $24 \mathrm{~h}$ at $37^{\circ} \mathrm{C}$ then rescued in complete growth media for $24 \mathrm{~h}$ prior to further experimentation.

Statistical analysis. All data were expressed as the mean \pm standard deviation unless otherwise specified. Statistically significant differences between groups were analyzed using ANOVA with multiple comparison Tukey's post hoc test to compare every condition with each other condition in the experiment, unless otherwise indicated. P-values $<0.05$ were considered to indicate a statistically significant difference. All statistical analyses were performed using GraphPad Prism 7.04 (GraphPad Software, Inc.).

RA pathway model. The RA model graphic was created with BioRender.com utilizing generic DNA, protein, cell membrane, and receptor images available on the website.

\section{Results}

$R A$ promotes neuroblastoma differentiation and is mediated via RORI. RA-mediated differentiation of SK-N-SH cells induced a change in phenotype from an epithelial-like state to a more typical neuronal-like state with distinct neurite processes. Concurrently the increase in neurite processes and lengths led to an increase in synaptic connections (Fig. 1C and D). Yellow arrows in phase contrast images point to marked neurite extensions or clusters of neurites that are suggestive of development (Fig. 1C). RA-induced differentiation was monitored via immunoblotting assessing the levels of synaptophysin, a ubiquitous synaptic marker (31). We assume that an indication in increased neurite length paired with an observation of increasing synaptophysin expression is indicative of the formation of synapses, suggesting differentiation. Furthermore, an increase in synaptophysin after $96 \mathrm{~h}$ of treatment, indicative of increased differentiation was observed (Fig. 1A and B). Notably, time-dependent modulation of ROR1 expression was also observed. ROR1 levels increased initially from 0 to $72 \mathrm{~h}$ and then significantly decreased at $96 \mathrm{~h}$ (Fig. 1A and B).
To investigate whether RA regulation of ROR1 expression was vital to the differentiation process, ROR1 was knocked down via shRNA (shROR1) and differentiation was monitored. A decrease in neurite length was observed in RA-treated cells with ROR1 knockdown when compared to a vector control (Fig. 1E and F). The synaptophysin levels were also monitored in shROR1-transfected cells following RA treatment and a decrease in synaptophysin levels was observed (Fig. 1E and F). Immunofluorescence labelling synaptophysin in shROR1 and vector-transfected cells, both treated with RA, similarly revealed impeded differentiation (Fig. 1G).

$R A$ regulation of ROR1 modulates the PI3K/AKT/GSK3 $\beta$ pathway. ROR1 is a Wnt pathway receptor that regulates cell migration, cell cycle progression, and apoptosis by promoting the PI3K/AKT/GSK3 $\beta$ signaling axis (14-17). To investigate the downstream effects of RA modulation of ROR 1 the PI3K/AKT/GSK3 $\beta$ pathway was monitored after RA treatment. An increase in AKT phosphorylation on serine 473 was observed, which is indicative of increased activation of the PI3K/AKT pathway (Fig. 2A and B). This was associated with increased phosphorylation and inhibition of GSK $3 \beta$ until $72 \mathrm{~h}$ (Fig. 2A and B). GSK3 $\beta$ phosphorylates $\beta$-catenin on Ser 33/37 inhibiting the activity of the latter, tagging it for proteasomal degradation (32). Corroborating the increase in GSK $3 \beta$ inhibition, a decrease in $\beta$-catenin phosphorylation was observed (Fig. 2A and B). This would suggest more active $\beta$-catenin. $\beta$-catenin activity was monitored using a luciferase reporter system containing TCF/LEF responsive elements and an increase in $\beta$-catenin activity after RA treatment from 0 to $96 \mathrm{~h}$ was observed (Fig. 2C). To confirm that RA modulation of the PI3K/AKT/GSK3 $\beta$ pathway was mediated via RA upregulation of ROR1, we knocked down ROR1 prior to RA treatment and similarly monitored PI3K/AKT/GSK3 $\beta$. A decrease in AKT activation and an increase in phosphorylation of GSK3 $\beta$ until the 72-h time-point, were observed. However, at $96 \mathrm{~h}, \mathrm{p}-\mathrm{AKT}$ and $\mathrm{p}-\mathrm{GSK} 3 \beta$ trends were reversed which is the suggested time of the end of differentiation (Fig. 2D and E). Fig. S2 depicts individual proteins from Fig. 2A baseline-corrected to the NT group. Fig. S3 depicts individual proteins from Fig. 2D baseline-corrected to the NT group.

$R A$ regulates the transcription of $R O R 1 /$ Wnt $5 a$. Subsequently, it was investigated how RA mechanistically regulates ROR1 expression. RA typically binds to and activates RAR, regulating the transcription of genes possessing RARE sequences (5'-AGGTCA-3') in the region upstream to their promoter $(9,10)$. ROR1 transcription was monitored after RA treatment and an increase in ROR1 mRNA from $0-72 \mathrm{~h}$ was observed, followed by a significant decrease at $96 \mathrm{~h}$ (Fig. 3B) mirroring our immunoblotting results in Fig. 1A. The transcription of the ligand of ROR1, Wnt5a, was also monitored after RA treatment and a similar trend was observed: An increase in Wnt5a mRNA from $0-72 \mathrm{~h}$ and then a significant decrease at $96 \mathrm{~h}$ (Fig. 3C). Analysis of the sequence upstream to the ROR1 promoter revealed the presence of two RARE sequences. Similarly, one RARE sequence was found in the region upstream to the Wnt5a promoter (Fig. 3A). 
B

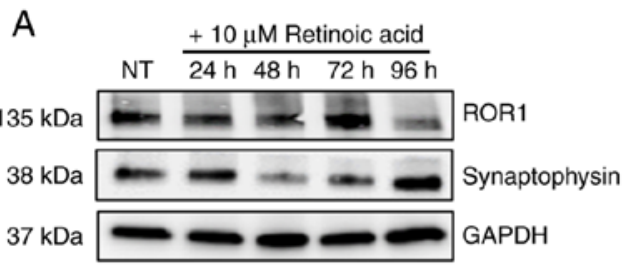

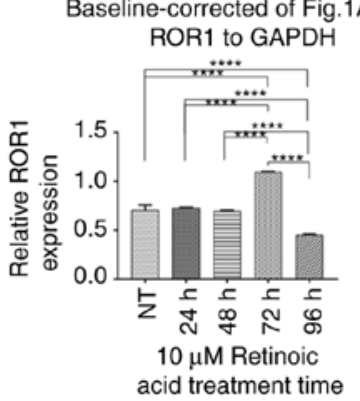

Baseline-corrected of Fig.1A

synaptophysin to GAPDH

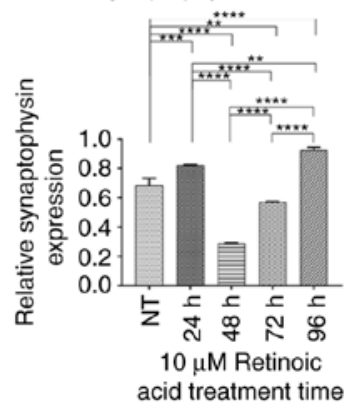

C

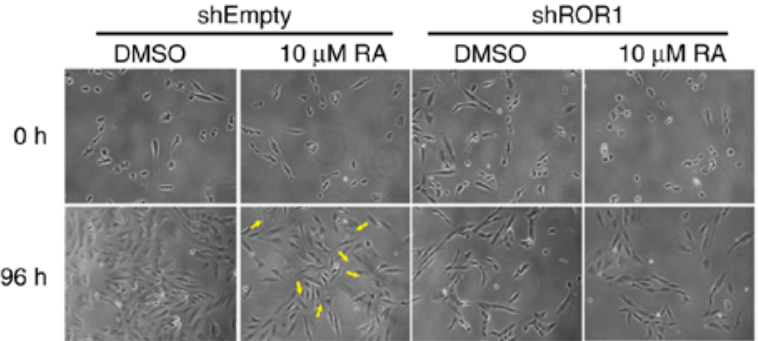

D Knockdown of ROR1 represses neurite length

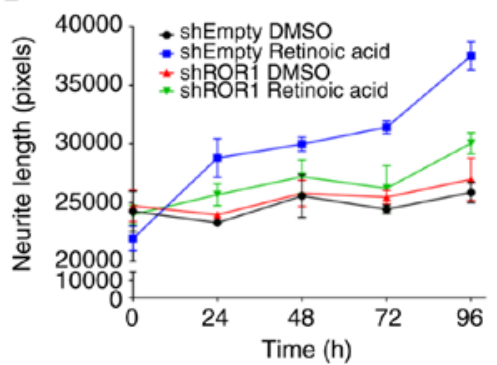

E DMSO $\frac{\text { shROR1 }+10 \mu \mathrm{M} \text { Retinoic acid }}{\mathrm{NT} 24 \mathrm{~h} 48 \mathrm{~h} 72 \mathrm{~h} 96 \mathrm{~h}}$

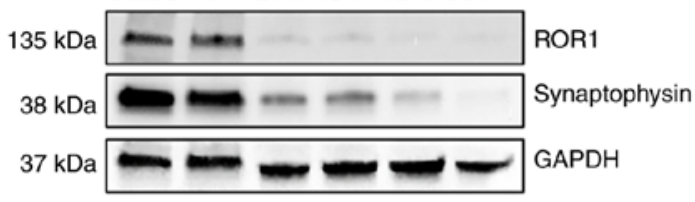

G

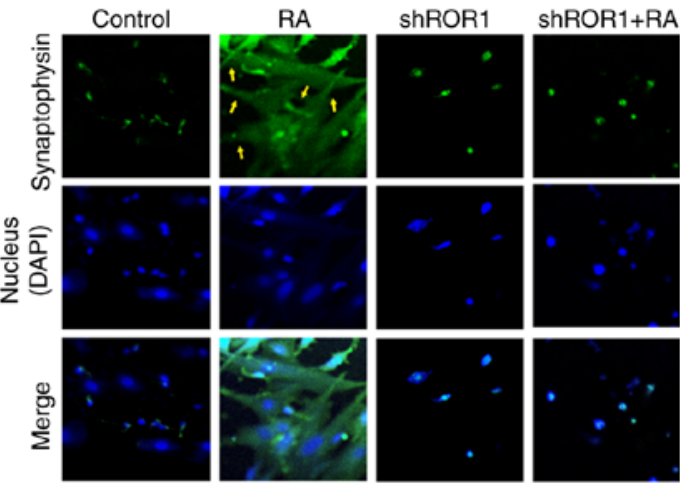

F Baseline-corrected of Fig.1E ROR1 to GAPDH Baseline-corrected of Fig.1E shROR1+10 $\mu$ M Retinoic acid treatment time

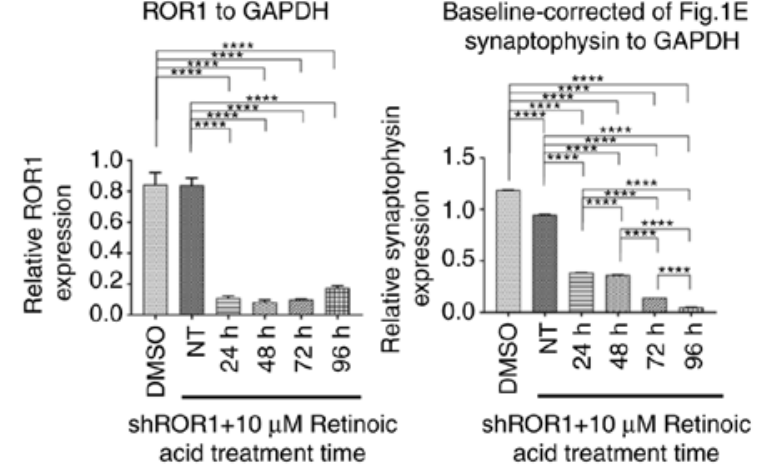

synaptophysin to GAPDH
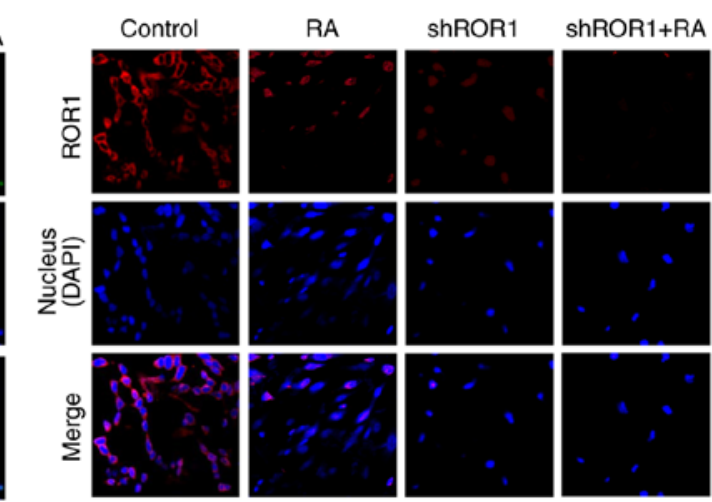

Figure 1. RA promotes NB differentiation via ROR1. (A) Immunoblotting revealed the changes in ROR1 and synaptophysin levels under normal differentiation with RA. (B) Densitometry of immunoblots from A, baseline-corrected to GAPDH (ANOVA with Tukey's multiple comparison to all conditions, n=3). ${ }^{* *} \mathrm{P}<0.005,{ }^{* * *} \mathrm{P}<.0005,{ }^{* * * *} \mathrm{P}<0.0001$. (C) Phase contrast images of SK-N-SH neuroblastoma cells undergoing RA or DMSO treatment over $96 \mathrm{~h}$ under shRNA test Lipofectamine transfection, knocking down ROR1 expression. Yellow arrows indicate marked neurite extensions that suggest development. (D) Visualization of the average neurite length over time following knockdown of ROR1 (n=3). (E) Immunoblots revealed the changes in ROR1 and synaptophysin levels after Lipofectamine transfection, knocking down ROR1 expression. (F) Densitometry of immunoblots from E, baseline-corrected to GAPDH (ANOVA with Tukey's multiple comparison test to compare each condition with every other condition in the experiment, $\mathrm{n}=3$ ). ${ }^{* * * *} \mathrm{P}<0.0001$. $(\mathrm{G})$ Immunofluorescence revealed the effects of RA on synaptophysin (green) levels with or without shRNA knockdown of ROR1 (red). DAPI (blue) highlights the nucleus of the neurons. Yellow arrows indicate marked neurite extensions. RA, retinoic acid; NB, neuroblastoma; ROR1, receptor tyrosine kinase-like orphan receptor 1; NT, not treated.

Next, it was investigated whether the presence of a RARE sequence was associated with increased RAR $\alpha$ binding to the ROR1 and Wnt5a promoters after RA treatment. ChIP of RAR $\alpha$ after RA treatment was performed and ROR1 and Wnt5a bound to RAR $\alpha$ were assessed via qPCR. In both instances, an increase in RAR $\alpha$ bound to the ROR1 or Wnt5a 
A

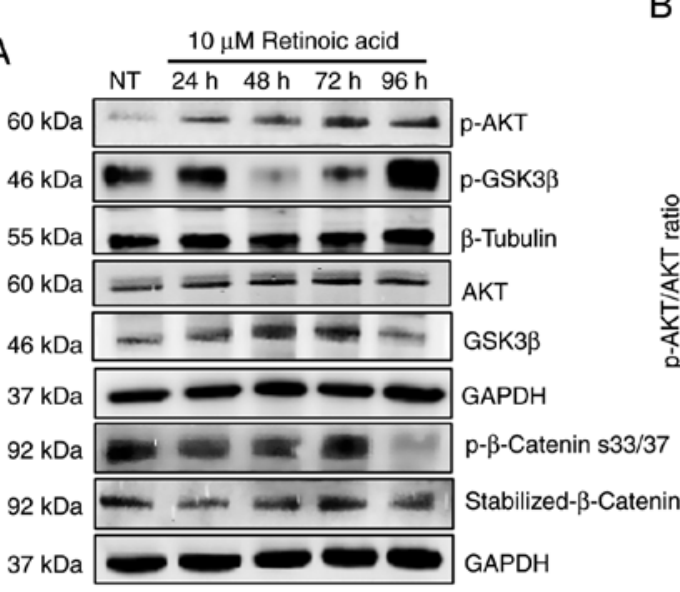

C

$\beta$-Catenin levels during differentiation

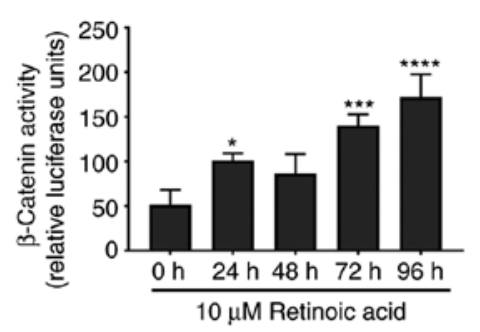

D

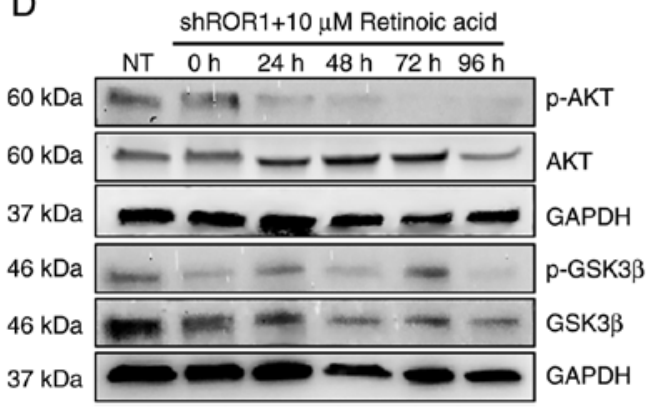

B

Baseline-corrected Fig. 2A p-AKT/AKT

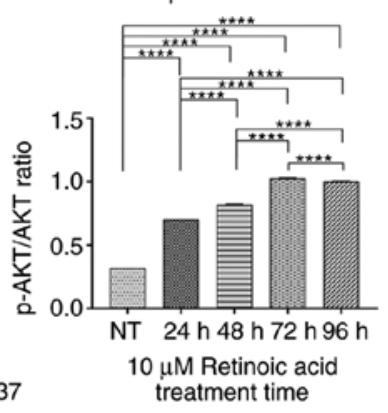

Baseline-corrected Fig. 2A p- $\beta$-Catenin/stabilized- $\beta$-Catenin

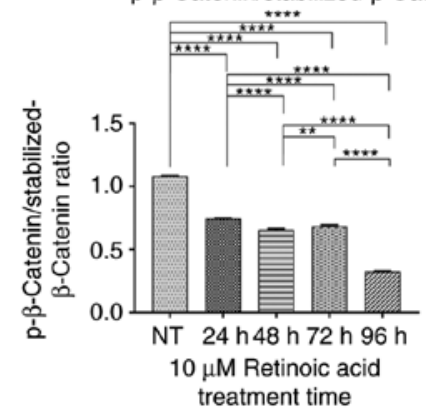

E
Baseline-corrected Fig. 2D p-AKT/AKT

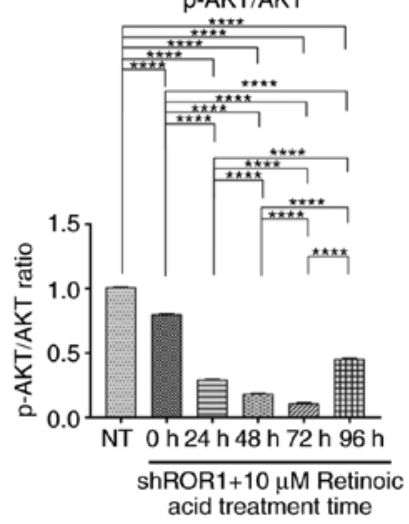

Baseline-corrected Fig. 2A p-GSK3 $\beta / G S K 3 \beta$

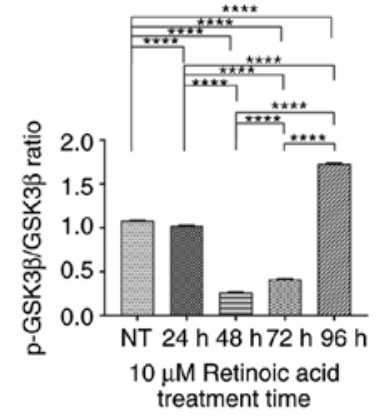


A

ROR1

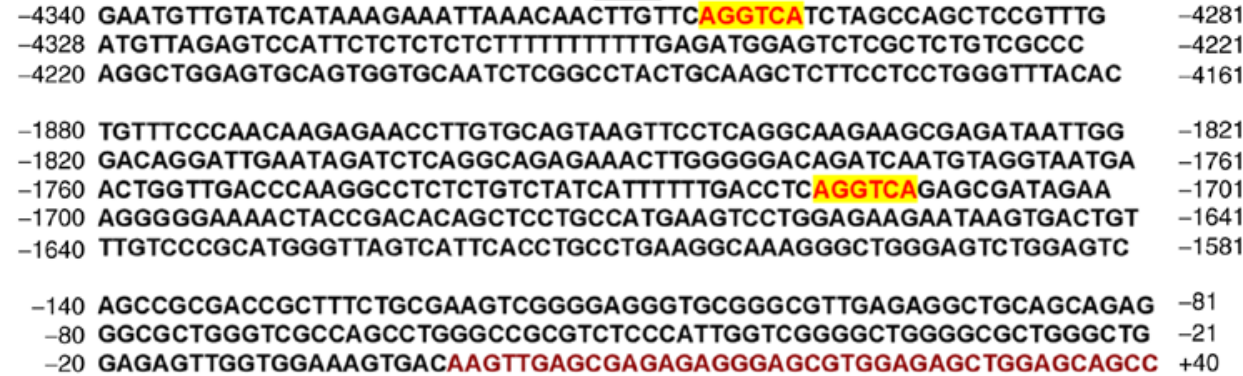

Wnt5a

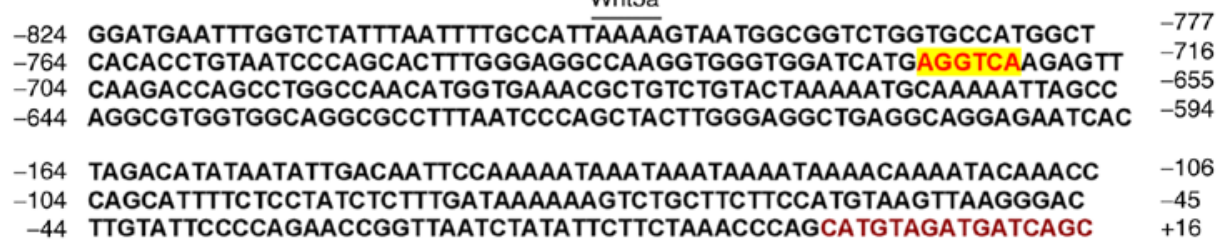

B

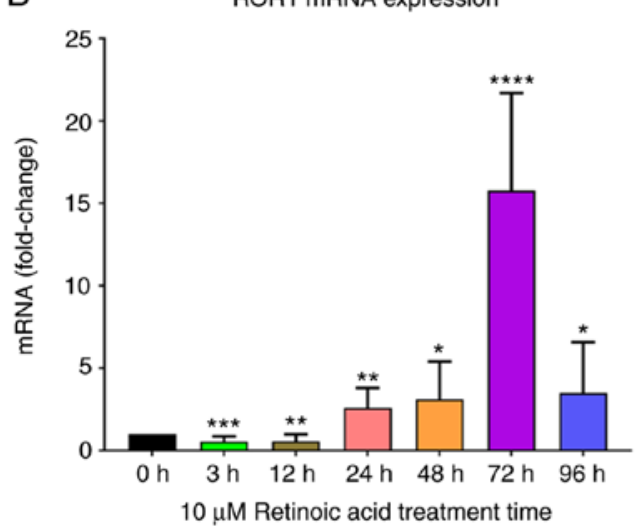

D

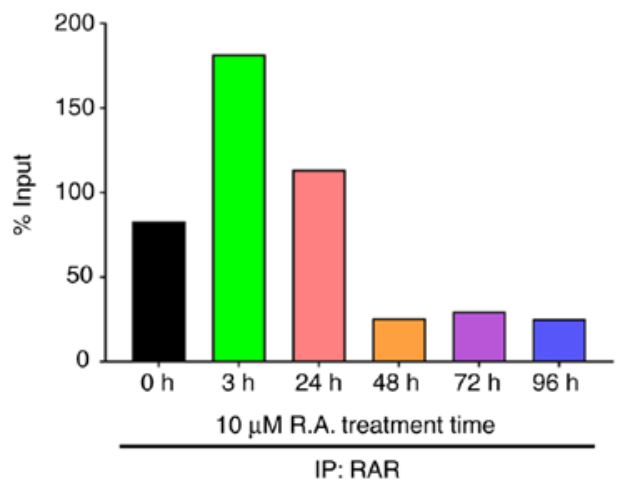

C

Wnt5a mRNA expression

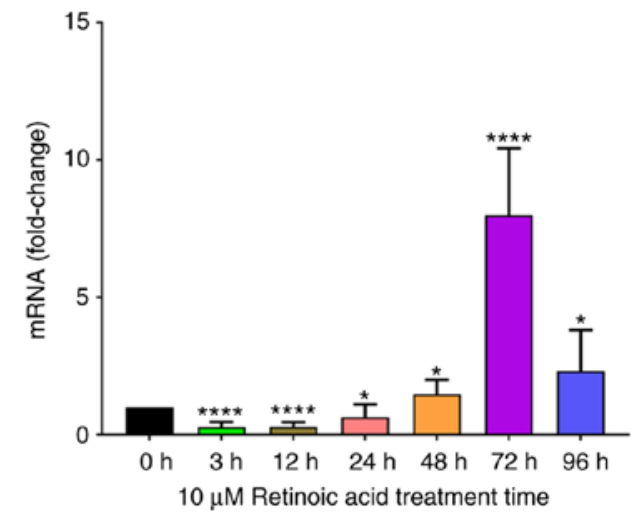

E

RARa bound to Wnt5a promoter

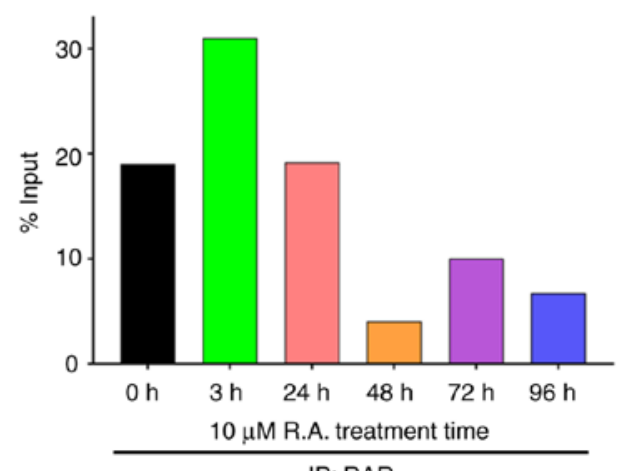

IP: RAR

Figure 3. RA regulates ROR1/Wnt5a transcription. (A) DNA sequences of the ROR1 and Wnt5a genes upstream to the first exon depicted with red text. The RARE regions which bind to the activated RAR are highlighted yellow. (B and C) qPCR results of ROR1 and Wnt5a mRNA collected during normal RA treatment over $96 \mathrm{~h}, \mathrm{n}=3 .{ }^{*} \mathrm{P}<0.05,{ }^{* *} \mathrm{P}<0.005,{ }^{* * *} \mathrm{P}<0.0005,{ }^{* * * *} \mathrm{P}<0.0001$. (D and $\left.\mathrm{E}\right) \mathrm{ChIP}$ of ROR1 and Wnt5a genes that has been bound to RAR during differentiation quantified by qPCR. RA, retinoic acid; ROR1, receptor tyrosine kinase-like orphan receptor 1; RARE, RA response element; RAR, RA receptor; ChIP, chromatin immunoprecipitation.

another dataset, GSE120920 (28), patient-derived xenograft cultures from two patients with high-risk, MYCN-amplified NB (NB-PDX2 and NB-PDX3), were treated with RA for 6 and $24 \mathrm{~h}$ and whole transcriptome analysis was performed via DRUG-Seq. Similarly, an increase in ROR1 mRNA in both cell cultures post-RA treatment was observed (Fig. 4C and D). There was no significant change in Wnt5a expression in the RA-treated groups compared to the control (Fig. S1C and D).

$R A$ effect on differentiation and RORI is RAR-dependent. RA induces differentiation via activation of RAR (33). However, RA has also been revealed to bind to and induce several other cellular regulators such as CRABP I and 
A

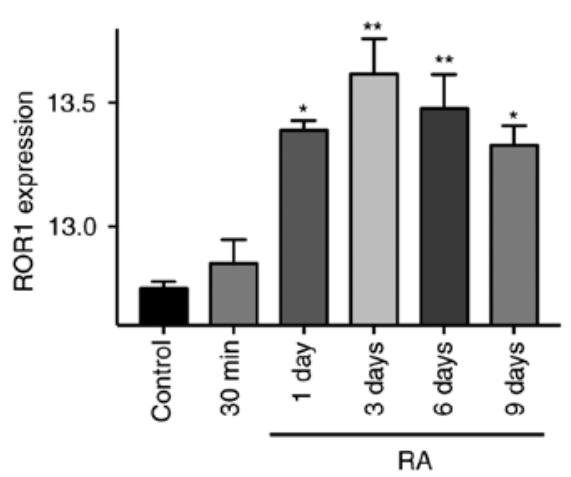

C

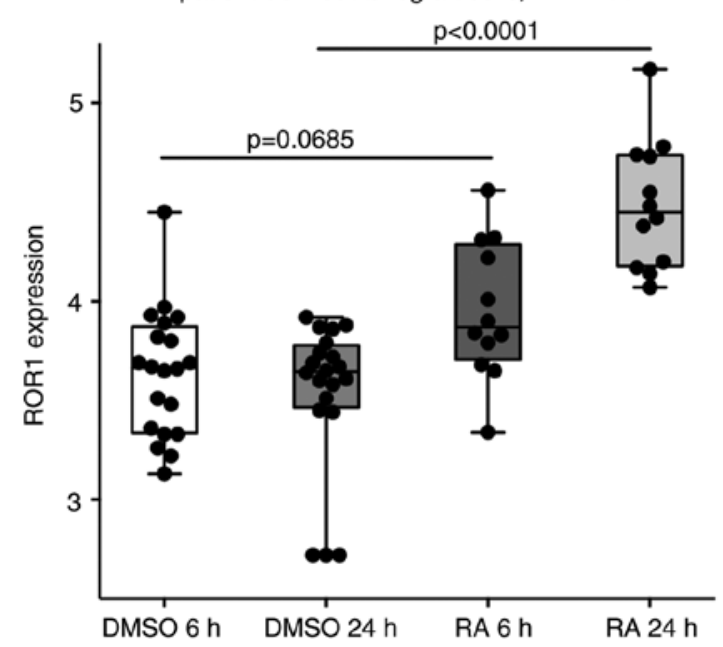

B

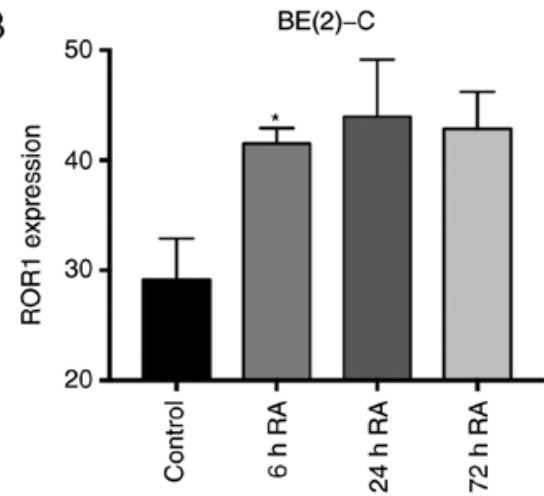

D

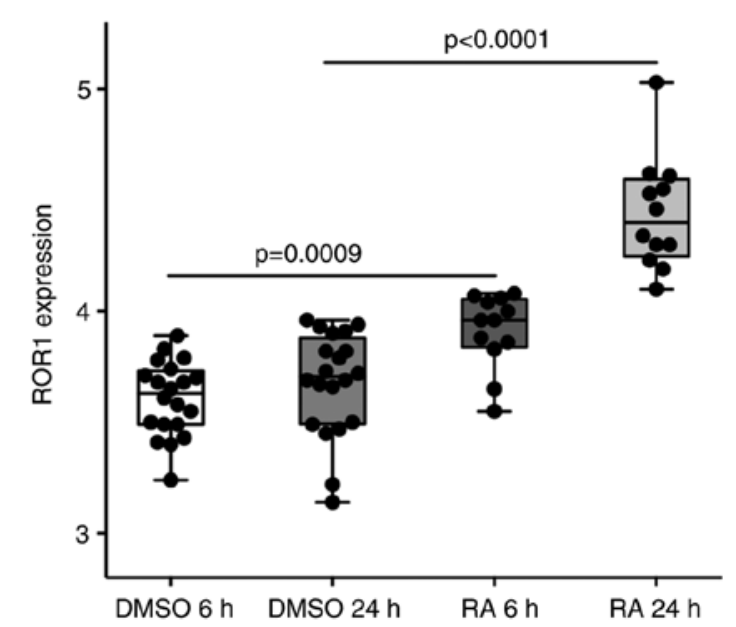

Figure 4. RA promotes ROR1 transcription in primary NB cells as well as other NB cell lines. (A) ROR1 mRNA levels in SH-SY5Y cells treated with $5 \mu \mathrm{M}$ RA for 30 min, 1, 3, 6 and 9 days or DMSO (control). NCBI GEO accession number: GSE58070; $n=2$. Statistical test via one-way ANOVA. "P<0.05, ${ }^{* *} \mathrm{P}<0.01$. (B) ROR1 mRNA levels in BE(2)-C cells treated with $5 \mu \mathrm{M}$ RA for 6, 24 and $72 \mathrm{~h}$ or DMSO (control). NCBI GEO accession number: GSE45587; $\mathrm{n}=3$. Statistical test via one-way ANOVA. "P<0.05. (C and D) ROR1 mRNA in NB patient-derived xenograft cells (C) NB-PDX2 and (D) NB-PDX3 treated with RA for 6 and $24 \mathrm{~h} ; \mathrm{n}=20$. The results are presented as the mean \pm standard deviation. Statistical test via one-way ANOVA with Tukey's multiple comparison test. RA, retinoic acid; ROR1, receptor tyrosine kinase-like orphan receptor 1; NB, neuroblastoma; GEO, Gene Expression Omnibus.

CRABP II which are involved in nervous system development (34). To verify whether RA-induced differentiation and upregulation of ROR1 was RAR-dependent, a RAR was inhibited using a high affinity RAR antagonist, AGN 193109 (RARi). Cells were pre-treated with RARi prior to RA treatment. Then, differentiation was assessed by measuring neurite length. As anticipated, neurite lengths were decreased in the cells pre-treated with RARi compared to cells that were not pretreated with RARi (Fig. 5A). RAR inhibition suppressed the effect of RA on ROR1 and therefore it was investigated whether overexpressing ROR1 in RARi pre-treated cells would rescue the differentiation phenotype. An increase in neurite lengths in RARi pre-treated cells after ROR1 overexpression was observed that was comparable to the RA-only group (Fig. 5A and B). To confirm the present findings, synaptophysin protein levels after RA treatment in cells with RAR inhibition and/or ROR1 overexpression were assessed. Corroborating our phenotypic findings in Fig. 5A, a decrease in synaptophysin in the RARi + RA group compared to the RA-only group was observed (Fig. 5C and D). ROR1 overexpression in these RARi + RA cells rescued synaptophysin expression (Fig. 5C and D). Fig. S4 provides proof of transfection based on RT-qPCR data for ROR1 expression due to the transfection of pROR1.

Based on these findings, we propose a model where treatment with RA leads to a cascade of downstream events initiated by ROR1, resulting in differentiation of neuronal cells. The ROR1-mediated effect is through the well-established PI3K/AKT/GSK3 $\beta$ pathway (Fig. 6).

\section{Discussion}

The data from the present study demonstrated that ROR1 regulated RA-induced differentiation by modulating RAR. In some instances, spontaneous recovery has occurred in patients as a result of differentiation of malignant tissue into normal, mature neural tissue (3). Thus, differentiation of malignant neuroblasts into normal mature neurons remains a key therapeutic strategy for neuroblastoma. RA, a vitamin A-derived morphogen, is a well-established differentiating agent that has shown promise clinically for neuroblastoma and other poorly-differentiated cancers, including lung, prostate, breast, bladder, oral and skin cancers (5,35-38). Understanding of the molecular mechanisms underlying RA-induced 

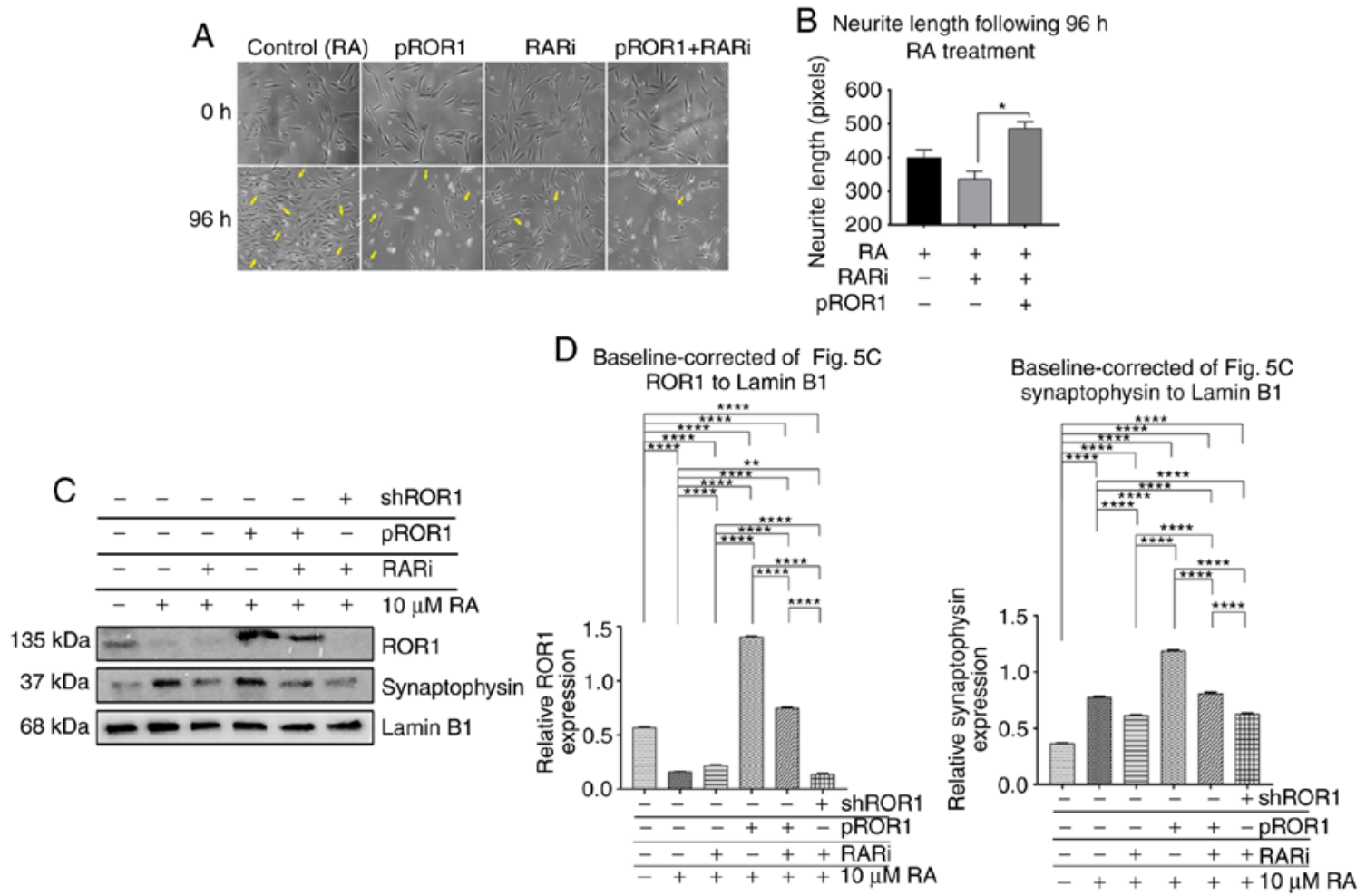

Figure 5. Effects of RA on ROR1 and differentiation is RAR-dependent. (A) Light-microscopic images (x100) after various treatments modulating the degree of ROR1 in the cell at 0 and $96 \mathrm{~h}$. Yellow arrows indicate marked neurite lengths and neurite clusters that suggest progression of development. (B) Visualization of average neurite length after ROR1-modulating treatments over $96 \mathrm{~h}(\mathrm{n}=3)$. ${ }^{*} \mathrm{P}<0.05$. (C) Immunoblots of synaptophysin and ROR1 after ROR1-modulating treatments. (D) Densitometric analysis of immunoblots in C assessing ROR1 and synaptophysin levels (ANOVA with Tukey's multiple comparison test to compare each condition with every other condition in the experiment, $\mathrm{n}=3) .{ }^{* *} \mathrm{P}<0.005,{ }^{* * * *} \mathrm{P}<0.0001$. RA, retinoic acid; ROR1, receptor tyrosine kinase-like orphan receptor 1; RAR, RA receptor.

differentiation remains limited. There are several genetic heterogeneities in neuroblastomas which include amplification of the MYCN oncogene, deletion of the distal short arm of chromosome 1 (1p), gain in the distal long arm in chromosome 17 (17q), and DNA ploidy (39). Neuroblastoma consists of tumorigenic ' $\mathrm{N}$ ' type (neuronal) and non-tumorigenic ' $\mathrm{S}$ ' type (Schwannian) cells. This cellular heterogeneity renders prognosis difficult. NB aggressiveness and poor prognosis is mainly associated with N-Myc amplification. Since the present study was focused on understanding the cellular mechanisms that regulated RA-induced differentiation, human neuroblastoma cell line SK-N-SH which is markedly heterogeneous was selected (40). SK-N-SH cells present a suitable model to study tumor-initiating neuroblasts as it has both cell types, as well as the 'I' cell type which is an intermediate of $S$ and $\mathrm{N}$ types (41). Furthermore, the time for in-vitro differentiation is significantly shorter and possibly more reliable in this cell line than other neuroblastoma cell lines, including the more studied SH-SY5Y cell line $(8,20)$. Hence, the data from the present study, obtained in a highly heterogeneous cell line such as SK-N-SH, is particularly relevant for highly heterogeneous tumors such as the ones found in NB patients.

The present data revealed that RA treatment promoted an initial increase in ROR1 protein and mRNA expression from 0-72 $\mathrm{h}$ which was associated with activation of the P13K/AKT growth pathway. The P13K/AKT pathway was previously revealed to play a role in RA-induced differentiation through proliferation and cell cycle progression $(17,42)$. ROR1 is an upstream activator of these pathways $(14,15,43)$. Downstream to the P13K/AKT pathway, activation of $\beta$-catenin activity, another pathway known to promote differentiation, was observed (32). ROR1 knockdown suppressed RA-induced differentiation indicating ROR1 as a key regulator of the process $(12,13,15)$.

Notably, ROR1 levels markedly decreased after $96 \mathrm{~h}$ of RA treatment. This corroborates previous findings suggesting markedly minimal ROR1 levels in normal neurons and other differentiated adult cells (15). The mechanism of ROR1 sequestering post-differentiation remains unknown. ROR1 can be rapidly degraded by the proteasome when Wnt5a levels are high in certain cases (44). In the present study, an increase in Wnt5a transcription following RA treatment from $0-72 \mathrm{~h}$, followed by a marked decrease at $96 \mathrm{~h}$ was observed. It is entirely plausible that excessive Wnt5a levels after $72 \mathrm{~h}$ aid in the sequestering of ROR1. This putative regulatory event would prevent ROR1-induced proliferation and motility in mature neurons. Furthermore, this suggests that the role of ROR1 is important for the process of differentiation and is modulated to decrease once differentiation is complete. This is consistent with the theory that ROR1 is generally low in adult cells and is upregulated in cancers and undifferentiated cells.

To investigate the mechanism of RA regulation of ROR1 and Wnt5a, RAR activity was probed. RAR is a transcriptional regulator induced by RA, responsible for most RA-induced molecular events (9). RAR is found consistently in neuroblastoma cell lines. It is a crucial protein in regard to development 


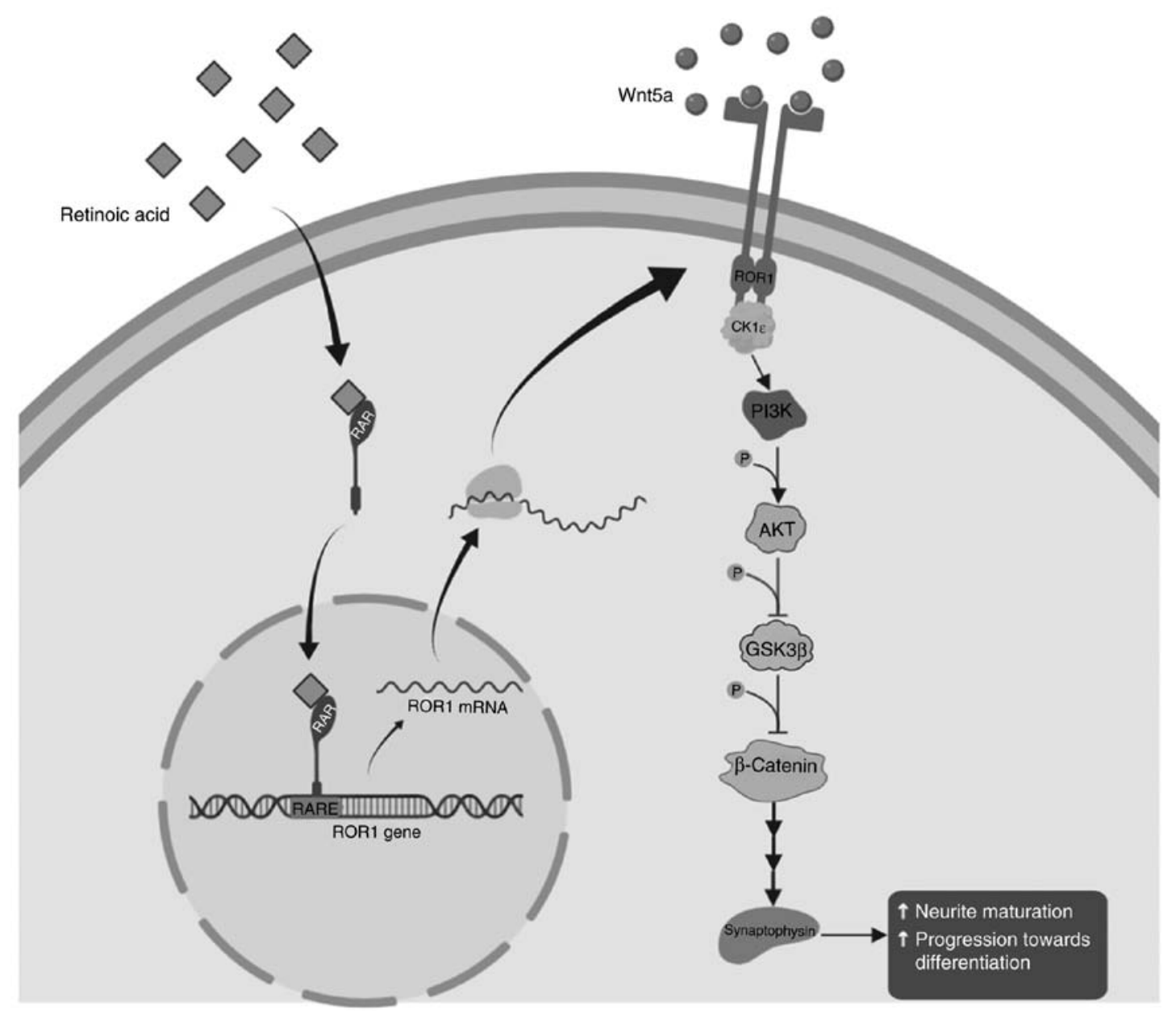

Figure 6. RA pathway model. The proposed proliferation and differentiation modulation pathway of RA. RA binds to RAR in the cytoplasm and migrates into the nucleus to act on RARE regions. Normal transcription and translation result in increased ROR1 and Wnt5a synthesis and the ROR1 signaling pathway cascades to synaptophysin as a node of differentiation as well as $\beta$-catenin-related growth and proliferation factors. The image was created using BioRender. RA, retinoic acid; ROR1, receptor tyrosine kinase-like orphan receptor 1; RAR, RA receptor; RARE, RA response element.

and differentiation and thus, are useful to target in complex diseases such as neuroblastoma $(7,11)$. Upon binding of RA, RAR bind to target DNA sequences containing a RARE sequence (5'AGGTCA3'), regulating their transcription (9). In fact, RAR may heterodimerize with RXR depending on the target gene (7). Although this is a characteristic that would be useful to characterize a transcription factor complex of a gene, our focus was on observing and targeting RAR since it are required regardless of heterodimerization with RXR. The downstream and intermediate targets of RA-induced RAR that promote neuronal differentiation has generally been studied inefficiently (11). However, we identified two RARE sequences in the region upstream to the ROR1 promoter, and one in the region upstream to the Wnt5a promoter. ChIP of RAR-bound chromatin revealed a rapid increase in RAR accumulation at the ROR1 and Wnt5a promoters $3 \mathrm{~h}$ after RA treatment. This was associated with an increase in ROR1 and Wnt5a transcription suggesting RAR as a mediator of RA-induced regulation of both proteins. Corroborating these findings, an increase in ROR1 and Wnt5a expression in other MYCN non-amplified (SH-SY5Y) and amplified (BE(2)-C), as well as primary NB patient-derived cells, was observed following RA treatment.

Since RA can also bind to other cellular regulators such as CRABP I and CRABP II (34), we investigated whether the observed effects on ROR 1 and differentiation were RAR-dependent. Using a high-affinity RAR inhibitor (AGN 193109), a decrease in RA-induced differentiation was confirmed. Overexpression of ROR1 rescued the differentiation phenotype suggesting a vital role for both the RAR and ROR1 in RA-induced differentiation.

Based on the present results, we propose a model where RA treatment induces ROR1 and Wnt5a transcription. Increased ROR1 and Wnt5a activate MAPK/ERK and $\mathrm{PI} 3 \mathrm{~K} / \mathrm{AKT}$ pathways to promote differentiation as previously observed (42).

The implications of this research are several-fold. Identifying ROR1 as a regulator of differentiation provides valuable insight into the molecular mechanisms underlying RA-induced differentiation. It also suggests that evaluating ROR1 levels prior to and during retinol differentiation therapy may have prognostic value. As ROR1 is a highly active oncogenic receptor (15), inducing its expression with RA may lead to unwanted outcomes. ROR1 has recently been evaluated as a therapeutic target for neuroblastoma $(45,46)$. In these ROR1 antagonist studies, concurrent efforts evaluating neuroblast differentiation may shed more light on the implications of ROR1 in neuroblast differentiation. However, these findings underline the vital role for growth pathway regulators in 
differentiation and further elucidate the molecular mechanisms regulating RA-induced differentiation.

\section{Acknowledgements}

The authors would like to thank Dr. Zachary Klase for support with research materials and instruments.

\section{Funding}

Funds for the present study, were provided through the Milton Lev Faculty Research Fund, an internal grant awarded to BP by The University of the Sciences.

\section{Availability of data and materials}

The datasets used and/or analyzed during the present study are available from the corresponding author on request.

\section{Authors' contributions}

All of the authors designed the study. AI and NF performed the experiments. AI and NF wrote the manuscript. BP revised the manuscript critically for important intellectual content. All authors reviewed, read, and approved the manuscript and agree to be accountable for all aspects of the research in ensuring that the accuracy or integrity of any part of the work are appropriately investigated and resolved.

\section{Ethics approval and consent to participate}

Not applicable.

\section{Patient consent for publication}

Not applicable.

\section{Competing interests}

The authors declare that they have no competing interests.

\section{References}

1. Mitchell WG, Davalos-Gonzalez Y, Brumm VL, Aller SK, Burger E, Turkel SB, Borchert MS, Hollar S and Padilla S: Opsoclonus-ataxia caused by childhood neuroblastoma: Developmental and neurologic sequelae. Pediatrics 109: 86-98, 2002.

2. Yahya FS and Al-Shami HA: Posterior mediastinal neuroblastoma masked as flaccid paraparesis in a 3 year child. Neurosciences (Riyadh) 24: 320-323, 2019.

3. Louis CU and Shohet JM: Neuroblastoma: Molecular pathogenesis and therapy. Annu Rev Med 66: 49-63, 2015.

4. Habib EE, El-Kashef AT and Fahmy ES: Management of neuroblastoma: A study of first-and second-line chemotherapy responses, a single institution experience. Oncol Rev 6: e3, 2012.

5. Mandal A: Neuroblastoma treatment. (online) NewsMedical.net. Available at: https://www.news-medical. net/health/Neuroblastoma-Treatment.aspx. Accessed Feb 27, 2019.

6. Adamson PC, Matthay KK, O'Brien M, Reaman GH, Sato JK and Balis FM: A phase 2 trial of all-trans-retinoic acid in combination with interferon-alpha2a in children with recurrent neuroblastoma or Wilms tumor: A pediatric oncology branch, NCI and children's oncology group study. Pediatr Blood Cancer 49: 661-665, 2007.
7. Reynolds CP, Matthay KK, Villablanca JG and Maurer BJ: Retinoid therapy of high-risk neuroblastoma. Cancer Lett 197: 185-192, 2003

8. Shipley MM, Mangold CA and Szpara ML: Differentiation of the SH-SY5Y human neuroblastoma cell line. J Vis Exp 17: 53193, 2016.

9. Canon E, Cosgaya JM, Scsucova S and Aranda A: Rapid effects of retinoic acid on CREB and ERK phosphorylation in neuronal cells. Mol Biol Cell 15: 5583-5592, 2004.

10. Allenby G, Bocquel MT, Saunders M, Kazmer S, Speck J, Rosenberger M, Lovey A, Kastner P, Grippo JF and Chambon P: Retinoic acid receptors and retinoid $X$ receptors: Interactions with endogenous retinoic acids. Proc Natl Acad Sci USA 90: 30-34, 1993.

11. Nagai J, Yazawa T, Okudela K, Kigasawa H, Kitamura H and Osaka H: Retinoic acid induces neuroblastoma cell death by inhibiting proteasomal degradation of retinoic acid receptor alpha. Cancer Res 64: 7910-7917, 2004.

12. Petrova IM, Malessy MJ, Verhaagen J, Fradkin LG and Noordermeer JN: Wnt signaling through the Ror receptor in the nervous system. Mol Neurobiol 49: 303-315, 2014.

13. Rangel MC, Bertolette D, Castro NP, Klauzinska M, Cuttitta F and Salomon DS: Developmental signaling pathways regulating mammary stem cells and contributing to the etiology of triple-negative breast cancer. Breast Cancer Res Treat 156: 211-226, 2016.

14. Fultang N, Illendula A, Chen B, Wu C, Jonnalagadda S, Baird N, Klase Z and Peethambaran B: Strictinin, a novel ROR1-inhibitor, represses triple negative breast cancer survival and migration via modulation of PI3K/AKT/GSK3ß activity. PLoS One 14: e0217789, 2019.

15. Borcherding N, Kusner D, Liu GH and Zhang W: ROR1, an embryonic protein with an emerging role in cancer biology. Protein Cell 5: 496-502, 2014.

16. Blanc E, Roux GL, Benard J and Raguenez G: Low expression of Wnt-5a gene is associated with high-risk neuroblastoma. Oncogene 24: 1277-1283, 2005.

17. Bastien J, Plassat JL, Payrastre B and Rochette-Egly C: The phosphoinositide 3-kinase/Akt pathway is essential for the retinoic acid-induced differentiation of F9 cells. Oncogene 25: 2040-2047, 2006.

18. Akkuratov EE, Wu J, Sowa D, Shah ZA and Liu L: Ouabain-induced signaling and cell survival in SK-N-SH neuroblastoma cells differentiated by retinoic acid. CNS Neurol Disord Drug Targets 14: 1343-1349, 2015.

19. Hämmerle B, Yañez Y, Palanca S, Cañete A, Burks DJ, Castel V and Font de Mora J: Targeting neuroblastoma stem cells with retinoic acid and proteasome inhibitor. PLoS One 8: e76761, 2013.

20. Niewiarowska-Sendo A, Patrzalek K, Kozik A and Guevara-Lora I: The effect of differentiation agents on inflammatory and oxidative responses of the human neuroblastoma cell line SK-N-SH. Acta Biochim Pol 62: 435-443, 2015.

21. Gassmann M, Grenacher B, Rohde B and Vogel J: Quantifying Western blots: Pitfalls of densitometry. Electrophoresis 30: 1845-1855, 2009.

22. Tan HY and Ng TW: Accurate step wedge calibration for densitometry of electrophoresis gels. Opt Commun 281: 3013-3017, 2008.

23. Pemberton K, Mersman B and Xu F: Using ImageJ to assess neurite outgrowth in mammalian cell cultures: Research data quantification exercises in undergraduate neuroscience lab. J Undergrad Neurosci Educ 16: A186-A194, 2008.

24. Clevers H: Wnt/beta-catenin signaling in development and disease. Cell 127: 469-480, 2006.

25. Livak KJ and Schmittgen TD: Analysis of relative gene expression data using real-time quantitative PCR and the 2(-Delta Delta C(T)) method. Methods 25: 402-408, 2001.

26. Wang Y, Chakravarty P, Ranes M, Kelly G, Brooks PJ, Neilan E, Stewart A, Schiavo G and Svejstrup JQ: Dysregulation of gene expression as a cause of cockayne syndrome neurological disease. Proc Natl Acad Sci USA 111: 14454-14459, 2014

27. Frumm SM, Fan ZP, Ross KN, Duvall JR, Gupta S, VerPlank L, Suh BC, Holson E, Wagner FF, Smith WB, et al: Selective HDAC1/HDAC2 inhibitors induce neuroblastoma differentiation. Chem Biol 20: 713-725, 2013.

28. Almstedt E, Elgendy R, Hekmati N, Rosén E, Wärn C, Olsen TK, Dyberg C, Doroszko M, Larsson I, Sundström A, et al: Integrative discovery of treatments for high-risk neuroblastoma. Nat Commun 11: 71, 2020. 
29. Ye C, Ho DJ, Neri M, Yang C, Kulkarni T, Randhawa R, Henault M, Mostacci N, Farmer P, Renner S, et al: DRUG-seq for miniaturized high-throughput transcriptome profiling in drug discovery. Nat Commun 9: 4307, 2018.

30. Koster J, Volckmann R, Zwijnenburg D, Molenaar P and Versteeg R: R2: Genomics analysis and visualization platform. Cancer Res: 2490, 2019.

31. Tarsa L and Goda Y: Synaptophysin regulates activity-dependent synapse formation in cultured hippocampal neurons. Proc Natl Acad Sci USA 99: 1012-1016, 2002.

32. Rogers HA, Ward JH, Miller S, Lowe J, Coyle B and Grundy RG: The role of the WNT/B-catenin pathway in central nervous system primitive neuroectodermal tumours (CNS PNETs). Br J Cancer 108: 2130-2141, 2013.

33. Kam RK, Deng Y, Chen Y and Zhao H: Retinoic acid synthesis and functions in early embryonic development. Cell Biosci 2: 11, 2012.

34. Donovan M, Olofsson B, Gustafson AL, Dencker L and Eriksson U: The cellular retinoic acid binding proteins. J Steroid Biochem Mol Biol 53: 459-465, 1995.

35. Lindley D, Goranov B, Ponthan F and Redfern C: Abstract\# 5280: The role of retinoic acid receptors in differentiation, gene expression and apoptosis of neuroblastoma. Cancer Res 69 (9 Suppl): S5280, 2009.

36. Kedishvili NY: Retinoic acid synthesis and degradation. Subcell Biochem 81: 127-161, 2016.

37. Peinemann F, van Dalen EC, Enk H and Berthold F: Retinoic acid postconsolidation therapy for high-risk neuroblastoma patients treated with autologous haematopoietic stem cell transplantation. Cochrane Database Syst Rev 8: CD010685, 2017.

38. Chen MC, Hsu SL, Lin H and Yang TY: Retinoic acid and cancer treatment. Biomedicine (Taipei) 4: 22, 2014.

39. Bown N: Neuroblastoma tumour genetics: Clinical and biological aspects. J Clin Pathol 54: 897-910, 2001.
40. Boeva V, Louis-Brennetot C, Peltier A, Durand S, Pierre-Eugene C, Raynal V, Etchevers HC, Thomas S, Lermine A, Daudigeos-Dubus E, et al: Heterogeneity of neuroblastoma cell identity defined by transcriptional circuitries. Nat Genet 49: 1408-1413, 2017.

41. Ross RA, Biedler JL and Spengler BA: A role for distinct cell types in determining malignancy in human neuroblastoma cell lines and tumors. Cancer Lett 197: 35-39, 2003.

42. Qiao J, Paul P, Lee S, Qiao L, Josifi E, Tiao JR and Chung DH: PI3K/AKT and ERK regulate retinoic acid-induced neuroblastoma cellular differentiation. Biochem Biophys Res Commun 424: 421-426, 2012.

43. Fultang N, Illendula A, Lin J, Pandey MK, Klase Z and Peethambaran B: ROR1 regulates chemoresistance in Breast Cancer via modulation of drug efflux pump ABCB1. Sci Rep 10: 1821,2020

44. O'Connell MP, Marchbank K, Webster MR, Valiga AA, Kaur A, Vultur A, Li L, Herlyn M, Villanueva J, Liu Q, et al: Hypoxia induces phenotypic plasticity and therapy resistance in melanoma via the tyrosine kinase receptors ROR1 and ROR2. Cancer Discov 3: 1378-1393, 2013.

45. Park H, Awasthi A, Ayello J, Chu Y, Riddell SR, Rosenblum J, Lee DA and Cairo MS: ROR1-specific chimeric antigen receptor (CAR) NK cell immunotherapy for high risk neuroblastomas and sarcomas. Biol Blood Marrow Transplant 23: S136-S137, 2017.

46. Dave H, Butcher D, Anver M and Bollard CM: ROR1 and ROR2-novel targets for neuroblastoma. Pediatr Hematol Oncol 36: 352-364, 2019.

This work is licensed under a Creative Commons Attribution-NonCommercial-NoDerivatives 4.0 International (CC BY-NC-ND 4.0) License. 